\title{
Survival analysis of patients with stage IV gastric cancer following palliative surgery based on inflammation-based prognostic score
}

Takeshi Matsubara*, Noriyuki Hirahara, Toshihiro Takanashi, Shuichi Ishibashi and Yoshitsugu Tajima

Department of Digestive and General Surgery, Shimane University Faculty of Medicine, Shimane 693-8501, Japan

\begin{abstract}
Objective: The Glasgow Prognostic Score (GPS) has been demonstrated to be a useful prognostic factor for various tumors. The aim of the current study was to clarify the significance of the GPS for predicting postoperative survival of patients with stage IV gastric cancer after receiving palliative surgery.

Summary of background data: Generally stage IV gastric cancer is not considered for curative surgery. However, palliative surgery is often required to improve the quality of life of patients.

Methods: 51 consecutive patients with stage IV gastric cancer was performed the association between GPS, clinicopathological factors and overall survival was assessed.

Results: Peritoneal lavage cytology (CY), P0CY1 (no peritoneal dissemination and CY positive), surgical treatment, operative time and curability factors were correlated well with the GPS score. The number of metastatic sites ( 1 vs. $\geqq 2)$, curability (R0, R1 vs. R2) and GPS score (0, 1 vs. 2$)$ were found to be the independent prognostic factor. The prognosis of patients with a high GPS was significantly poor.

Conclusion: In patients with a GPS of 2, surgical treatment offered only few benefits to the patients and, thus, less invasive treatment should be recommended for these patients.
\end{abstract}

\section{Introduction}

Gastric cancer is the fourth most common cancer in the world and the second most frequent cause of death in the East [1]. In Japan, the incidence of gastric cancer has decreased, but it remains the most frequent cause of death among patients with malignant tumor [2]. Despite recent improvements in surgical techniques and adjuvant chemotherapies, the long-term survival of patients with advanced gastric cancer is still unsatisfactory [3]. The prognosis of patients with incurable advanced gastric cancer, i.e., stage IV gastric cancer, is dismal and most of them die within 1 year $[4,5]$.

In general, patients with stage IV gastric cancer are not good candidates for surgical resection and an effective palliation can usually be accomplished with systemic chemotherapy. However, these patients present with various clinical symptoms, such as abdominal pain, weight loss, cachexia and gastrointestinal bleeding, perforation or obstruction. Palliative surgery, defined as a surgical procedure designed to alleviate symptoms and to prevent the appearance of complications, is therefore required to improve the quality of life of patients [6,7]. On the other hand, a highly invasive surgery may result in unfavorable outcome and there have been a few indicators useful for deciding whether a surgery or medical management plan would be more beneficial to the individual patients with stage IV gastric cancer.

Several histopathological indicators are established as tumorrelated prognostic factors. In addition, the association between hypoalbuminemia and poor prognosis in patients with cancer has been well recognized and several inflammation-based prognostic scoring systems, including Glasgow Prognostic Score (GPS), have been introduced as useful indicators for prognosis of patients with malignant tumor $[7,8]$.

The GPS system comprises only the serum levels of C-reactive protein (CRP) and albumin. Recently, modified GPS (mGPS), which uses modified cut-off values for CRP and albumin, is also recognized as a useful prognostic factor for gastric cancer [9-12]. However, there has been no GPS analysis for patients with stage IV gastric cancer who underwent palliative surgery due to cancer-related clinical symptoms. The aim of this study was to clarify the prognostic value of the GPS in patients with stage IV gastric cancer undergoing palliative surgery.

\section{Material and methods}

\section{Patients}

A total of 352 patients with gastric cancer underwent surgery at our institute from January 2009 to April 2014. Of these, 51 patients received palliative surgery for stage IV gastric cancer. We retrospectively

Correspondence to: Dr. Takeshi Matsubara, Department of Digestive and General Surgery, Shimane University Faculty of Medicine, 89-1 Enya-cho, Izumo, Shimane 693-8501, Japan; Tel +81-853-20-2232; Fax +81-853-20-2229; E-mail: nanadai@med.shimane-u.ac.jp

Key words: Stage IV gastric cancer, Glasgow Prognostic Score, prognosis

Received: January 03, 2017; Accepted: January 24, 2017; Published: January 27, 2017 
reviewed the database of these 51 patients. Data on outcome of the patients were obtained from the patient clinical records. The study group comprised of 34 men and 17 women, with a mean age of 71.2 years (range; 25-92).

\section{Surgical procedure}

Palliative surgery was defined as a surgical procedure designed to alleviate cancer-related symptoms and to prevent the appearance of complications [6,7].

Gastrectomy, either a distal gastrectomy or a total gastrectomy, was performed by open or laparoscopic technique in 39 patients, in whom the tumor had no invasion to the neighboring organs, followed by Roux-en-Y reconstruction. The dissection of lymph nodes was limited, but an extended lymph node dissection in one patient and resection of synchronous liver metastasis in one resulted in no residual tumor (R0) operation. Fourteen patients resulted in microscopic residual tumor (R1) operation due to peritoneal cytology positive (CY1).

In the remaining 12 patients, bypass operation in a fashion of uncut Roux-en-Y gastrojejunostomy was performed because a poor general condition was evident in these patients due to locally advanced tumors located in the distal portion of the stomach. The survival time was defined as the duration from the date of surgical treatment to death. The pathological diagnosis and classification of the diseases were made according to the Japanese classification of gastric cancer [13].

\section{Inflammation-based prognostic scores}

The GPS was determined as previously described [14]. Patients without either an elevated CRP level $(>0.5 \mathrm{mg} / \mathrm{dL})$ or hypoalbuminemia $(<3.5 \mathrm{mg} / \mathrm{dL})$ were assigned as a GPS of 0 . Patients who presented with one of these biochemical abnormalities were assigned a GPS of 1 and patients showing both two abnormalities were assigned as a GPS of 2 . The association between GPS, clinicopathological factors and overall survival was assessed.

\section{Statistical analysis}

Means and standard deviations were calculated and differences were identified using Student's t test. Differences in continuous and categorical variables were evaluated by using analysis of variance (ANOVA) and chi-squared test, respectively. The survival rates were calculated according to the Kaplan-Meier method and differences were evaluated by the log-rank test. Cox's proportional hazards regression model was used to identify prognostic factors for survival. The variables with $\mathrm{P}$ values $\mathrm{p}<0.2$ for univariate analysis were entered into multivariate analysis.

\section{Results}

\section{Relationships between clinicopathological characteristics and GPS in stage IV gastric cancer}

The number of patients with GPS 0,1 and 2 was 26 (51.0\%), 11 (21.6\%) and 14 (27.5\%), respectively. According to the GPS score, we classified the patients into 2 groups as to be low GPS group (score 0 or 1 ) and high GPS group (score 2$)$. Thirty-seven patients $(72.5 \%)$ had a low GPS and 14 patients (27.5\%) showed a high GPS.

The relationship between GPS and clinicopathological features are shown in Table 1. The GPS had a significant correlation with peritoneal cytology (CY), P0CY1 (no peritoneal dissemination and CY positive), surgical treatment, operative time and curability.
Table 1. Relationships between clinicopathological features and GPS

\begin{tabular}{|c|c|c|c|}
\hline & GPS 0/1 (N=37) & GPS $2(N=14)$ & p-Value \\
\hline Age (mean) & 70.9 & 70.2 & N.S. \\
\hline Gender & & & N.S. \\
\hline Male & $25(68 \%)$ & $9(64 \%)$ & \\
\hline Female & $12(32 \%)$ & $5(36 \%)$ & \\
\hline ASA-PS & & & N.S. \\
\hline$\leqq 2$ & $33(89 \%)$ & $11(79 \%)$ & \\
\hline$>3$ & $4(11 \%)$ & $3(21 \%)$ & \\
\hline Histology & & & N.S. \\
\hline Well or moderately & $12(32 \%)$ & $8(57 \%)$ & \\
\hline Poorly/undifferentiated & $25(68 \%)$ & $6(43 \%)$ & \\
\hline Number of metastatic site & & & N.S. \\
\hline$\leqq 1$ & $28(76 \%)$ & $9(64 \%)$ & \\
\hline$\geqq 2$ & $9(24 \%)$ & $5(36 \%)$ & \\
\hline Peritoneal metastasis $(\mathrm{P})$ & & & N.S. \\
\hline Positive & $17(46 \%)$ & $10(71 \%)$ & \\
\hline Negative & $20(54 \%)$ & $4(29 \%)$ & \\
\hline Peritoneal cytology (CY) & & & 0.03 \\
\hline Positive & $26(70 \%)$ & $5(36 \%)$ & \\
\hline Negative & $11(30 \%)$ & $9(64 \%)$ & \\
\hline P0CY1 & & & 0.03 \\
\hline Positive & $13(35 \%)$ & $1(7 \%)$ & \\
\hline Negative & $24(65 \%)$ & $13(93 \%)$ & \\
\hline Liver metastasis $(\mathrm{H})$ & & & N.S. \\
\hline Positive & $6(16 \%)$ & $4(29 \%)$ & \\
\hline Negative & $31(84 \%)$ & $10(71 \%)$ & \\
\hline Para-aortic LNs metastasis & & & N.S. \\
\hline Positive & $3(8 \%)$ & $2(14 \%)$ & \\
\hline Negative & $34(92 \%)$ & $12(86 \%)$ & \\
\hline Other distant metastasis & & & N.S. \\
\hline Positive & $2(5 \%)$ & $3(21 \%)$ & \\
\hline Negative & $35(95 \%)$ & $11(79 \%)$ & \\
\hline Surgical treatment & & & 0.02 \\
\hline Resection (gastrectomy) & $32(86 \%)$ & $7(50 \%)$ & \\
\hline Bypass & $5(14 \%)$ & $7(50 \%)$ & \\
\hline Surgical procedure & & & N.S. \\
\hline Laparoscopy & $17(46 \%)$ & $5(36 \%)$ & \\
\hline Open & $20(54 \%)$ & $9(64 \%)$ & \\
\hline Operative time (median) & 396 & 285 & $<0.01$ \\
\hline Postoperative complication & & & N.S. \\
\hline Positive & $19(51 \%)$ & $6(43 \%)$ & \\
\hline Negative & $18(49 \%)$ & $8(57 \%)$ & \\
\hline Curability & & & 0.01 \\
\hline $\mathrm{R} 0$ or $\mathrm{R} 1$ & $15(35 \%)$ & $1(7 \%)$ & \\
\hline $\mathrm{R} 2$ & $22(65 \%)$ & $13(93 \%)$ & \\
\hline Chemotherapy & & & N.S. \\
\hline Yes & $28(76 \%)$ & $8(57 \%)$ & \\
\hline No & $9(24 \%)$ & $6(43 \%)$ & \\
\hline
\end{tabular}

\section{Prognostic factors of stage IV gastric cancer}

The results of univariate Cox proportional hazard regression analysis are shown in Table 2. Gastric resection (resection vs. bypass), $\mathrm{R} 0 / 1$ resection (R0, $1 v s$. R2), use of perioperative chemotherapy (yes $v s$. no) and low GPS score $(0,1 v s$. 2) were significantly correlated with a better patient prognosis. Furthermore, the young age ( $\leqq 75 v s .>75)$, low American Society of Anesthesiologists Physical Status classification (ASA-PS) (1,2vs. $\geqq 3)$, small number of metastatic sites ( $1 v s . \geqq 2)$ and no peritoneal metastasis (negative vs. positive) tended to have a better prognosis. 
Table 2. Univariate analyses on overall survival.

\begin{tabular}{|l|c|c|c|c|}
\hline & Category & HR & $\mathbf{9 5 \%}$ CI & p-Value \\
\hline Age & $>75$ & 1.278 & $0.920-1.776$ & 0.14 \\
\hline Gender & Male & 1.114 & $0.789-1.626$ & 0.55 \\
\hline ASA-PS & $\geqq 3$ & 1.468 & $0.856-2.262$ & 0.15 \\
\hline Histology & Por/undif. & 1.22 & $0.879-1.692$ & 0.23 \\
\hline Number of metastatic site & $\geqq 2$ & 1.335 & $0.926-1.873$ & 0.12 \\
\hline Peritoneal metastasis (P) & Positive & 1.399 & $0.995-1.988$ & 0.05 \\
\hline Peritoneal cytology (CY) & Positive & 0.838 & $0.605-1.161$ & 0.28 \\
\hline Liver metastasis (H) & Positive & 1.276 & $0.850-1.825$ & 0.23 \\
\hline LNs metastasis (Para-aorta) & Positive & 1.393 & $0.772-2.033$ & 0.28 \\
\hline Other distant metastasis & Positive & 1.631 & $0.941-2.558$ & 0.08 \\
\hline Surgical treatment & Bypass & 1.56 & $1.065-2.217$ & 0.02 \\
\hline Surgical procedure & Open & 1.11 & $0.797-1.580$ & 0.54 \\
\hline Postoperative complication & Positive & 1.218 & $0.862-1.718$ & 0.26 \\
\hline Curability & R2 & 1.961 & $1.292-3.279$ & $<0.01$ \\
\hline Chemotherapy & None & 1.527 & $1.069-2.132$ & 0.02 \\
\hline GPS & High & 1.698 & $1.206-2.353$ & $<0.01$ \\
\hline
\end{tabular}

Por/undif.: Poorly/undifferentiated

Table 3. Multivariate analysis on overall survival.

\begin{tabular}{|l|c|c|c|c|}
\hline & Category & HR & $\mathbf{9 5 \%}$ CI & p-Value \\
\hline Age & $>75$ & 1.370 & $0.925-2.028$ & 0.12 \\
\hline ASA-PS & $\geqq 3$ & 1.264 & $0.644-2.331$ & 0.48 \\
\hline Number of metastatic site & $\geqq 2$ & 1.481 & $1.081-2.212$ & 0.04 \\
\hline Peritoneal metastasis (P) & Positive & 1.030 & $0.653-1.678$ & 0.90 \\
\hline Other distant metastasis & Positive & 0.990 & $0.539-1.675$ & 0.97 \\
\hline Surgical treatment & Bypass & 1.254 & $0.811-2.290$ & 0.23 \\
\hline Curability & R2 & 2.358 & $1.218-4.975$ & 0.01 \\
\hline Chemotherapy & None & 1.404 & $0.944-2.032$ & 0.09 \\
\hline GPS & High & 1.898 & $1.240-2.890$ & $<0.01$ \\
\hline
\end{tabular}

Table 3 shows the results of multivariate analysis of 9 factors related to postoperative survival, including 5 variables with $\mathrm{p}<0.05$ and 4 variables with $\mathrm{p}<0.2$ in univariate analyses. Of these variables, number of metastatic sites ( $1 v s$. $\geqq 2$ ), curability (R0, $1 v s$. R2) and the GPS score $(0,1$ vs. 2$)$ were proved to be independent prognostic factors for survival.

\section{Overall survival and GPS}

As shown in Figure 1, the median survival time of patients with a low GPS and a high GPS was 588 days and 129 days, respectively, and patients with a high GPS showed a significantly poor survival $(\mathrm{p}<0.05)$.

\section{Overall survival and GPS in association with palliative surgeries}

Among patients who underwent $\mathrm{R} 2$ operation, the median survival time of patients with a low GPS and a high GPS were 587 days and 120 days, respectively on Figure 2. Among patients who received bypass operation, the median survival time of patients with a low GPS and a high GPS were 309 days and 120 days, respectively on Figure 3. Accordingly, patients with a high GPS showed a significantly poor survival irrespective of receiving either $\mathrm{R} 2$ resection or bypass operation $(\mathrm{p}<0.05)$.

\section{Discussion}

The prognosis of advanced gastric cancer with non-curable factors, such as distant organ metastasis and peritoneal dissemination, is poor. The majority of such patients with an advanced gastric cancer die within a year and the role of palliative surgery, including gastrectomy,

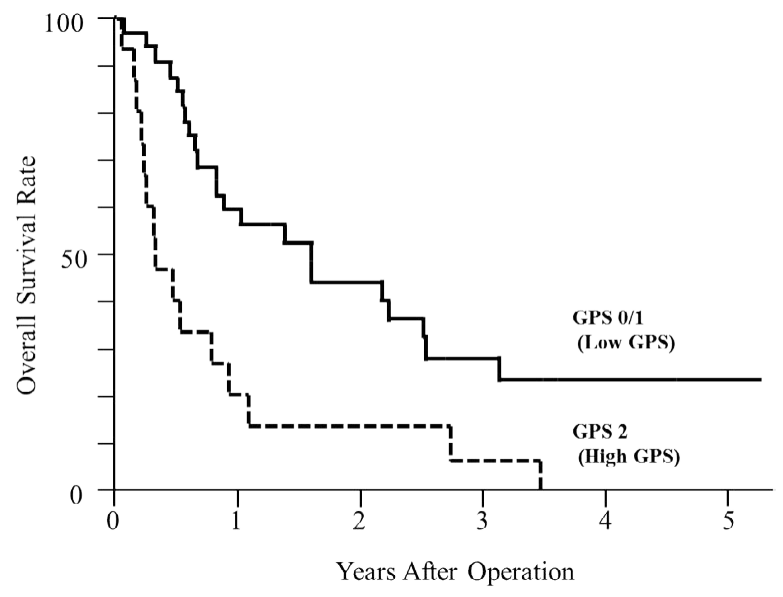

Figure 1.

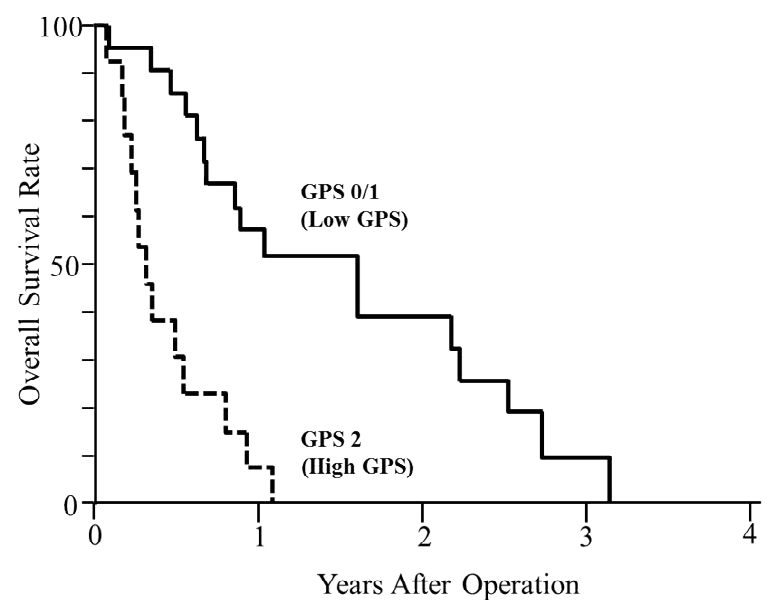

Figure 2.

for stage IV gastric cancer remains controversial. In patients with an advanced gastric cancer, the survival benefit of gastrectomy is reported to be restricted to patients with a single non-curable factor [15-17].

The indications for palliative surgery are generally determined by attending surgeons based on patients' condition, such as performance status, symptoms, extent of disease, and feasibility of resection. Recently, a randomized controlled trial (JCOG 0705) was conducted on patients with stage IV gastric cancer with a single non-curable factor [18]. However, the study could not demonstrate any benefit of palliative surgery when compared with systemic chemotherapy. At present, it is unclear whether palliative/curable surgery or chemotherapy should be recommended for patients with stage IV gastric cancer, especially in patients either with multiple non-curable factors, potentially resectable distant metastasis, or advanced age.

The host inflammatory response has an important role in the development and progression of cancer $[19,20]$. CRP is a nonspecific, but sensitive marker of systemic inflammatory response. Meanwhile, certain malignant cells can release inflammatory mediators and even $\mathrm{CRP}$, and a high level of serum CRP reflects an inflammatory response to tumor and is widely accepted as a reliable indicator of malignant potential and poor prognosis in several malignant tumors [10,21-23]. Hypoalbuminemia is known to be as a good index of malnutrition 


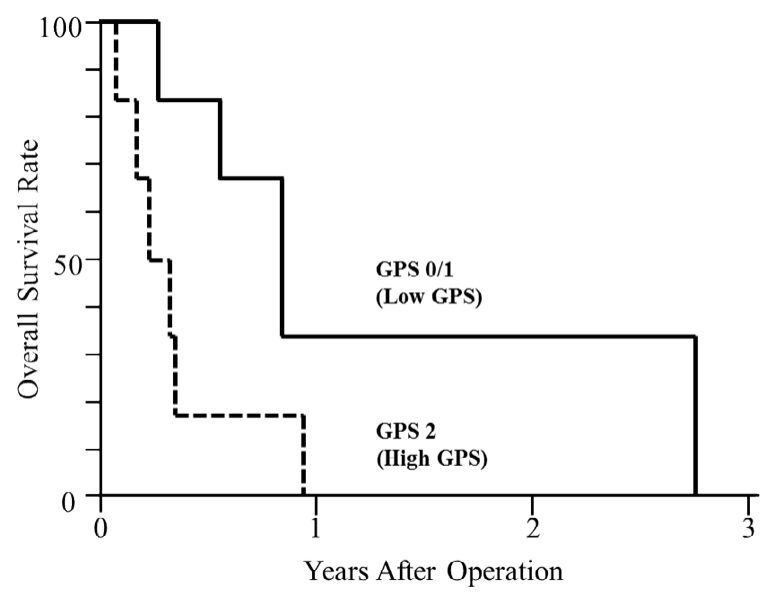

Figure 3.

and cachexia as well as a consequent presentation of systemic inflammation [24]. Several reports have suggested that the progression of hypoalbuminemia is likely to be a secondary event following serum elevation of CRP [25]. Thus, hypoalbuminemia and high levels of CRP may be regarded as a paraneoplastic phenomenon. Moreover, hypoalbuminemia is significantly associated with poor prognosis in patients with gastric cancer [26,27].

The GPS, which is composed of serum levels of CRP and hypoalbuminemia, may enable a better appreciation of the effects of tumor on both ongoing systemic inflammation and malnutrition.Since the GPS has been introduced to predict prognosis of patients with inoperable lung cancer firstly, there is increasing evidence of GPS for several malignant tumors including gastric cancer [11,24,28]. Although these previous studies reported the prognostic significance of GPS in several malignant diseases, to the best of our knowledge, no studies have demonstrated the role of preoperative GPS in predicting the outcome after palliative surgery for stage IV gastric cancer.

The present study revealed that the GPS was an independent prognostic factor for survival in patients with stage IV gastric cancer after receiving palliative surgery and the prognosis of patients with a high GPS was expected to be significantly poor. Since the GPS classification is simple, it could be a useful prognostic indicator for stage IV gastric cancer. Although there is a diverse range of views on the treatment for stage IV gastric cancer, little is known of which treatment, surgery or systemic chemotherapy, works best and has the greatest effect on survival of patients with stage IV gastric cancer [29]. Moreover, there is no evidence of what cases are suitable for surgery in patients with stage IV gastric cancer.

Some reports have suggested that palliative gastrectomy for stage IV gastric cancer may be associated with better survival [30]. In our study, it has become evident that the number of distant metastatic sites should be taken into account when palliative operation, including gastric resection, is planned for patients with stage IV gastric cancer because the presence of multiple distant metastatic sites was an independent factor for a poor survival. The stage IV gastric cancer includes a locally advanced gastric cancer with gastric obstruction and gastrojejunostomy may allow such cases to resume oral intake and to receive systemic chemotherapy after leaving outflow obstruction. In patients who underwent bypass operation, however, a poor survival was recognized when patients had a high GPS, compared to those with a low GPS, i.e., the median survival time was 120 days in the former and 309 days in the latter in this study. Among patients who underwent bypass surgery, moreover, the ratio of alleviation of various clinical symptoms was significantly lower in patients with a high GPS compared to those with a low GPS (data not shown).

$\mathrm{R} 2$ operation provided a better prognosis for patients with stage IV gastric cancer, but the benefit was restricted to patients with a low GPS since the median survival time was 587 days in the low GPS group and 120 days in the high GPS group, same as the result of bypass operation. Recently, a variety of endoscopic stents is available for the treatment of gastric obstruction due to malignant disease, and this procedure is less invasive than surgical management [31]. Because surgical treatment offered only few benefits to patients with a high GPS, less invasive treatment such as an endoscopic stent placement should be considered for these patients.

Although there were several potential limitations in our study, including retrospective single institution study with a small sample size and short follow-up observation, preoperative GPS analysis can be used as a prognostic indicator for survival in patients with stage IV gastric cancer. In patients with a high GPS, less invasive management such as an endoscopic stent placement should be considered when gastric obstruction occurs because either gastrectomy or bypass operation offers only few benefits for these patients.

\section{Authors' contributions}

TM and NH, TT and SI have been involved in drafting the manuscript or revising it critically for important intellectual content. YT has given final approval of the version to be published. All authors read and approved the final manuscript.

\section{References}

1. Crew KD, Neugut AI (2006) Epidemiology of gastric cancer. World J Gastroenterol 12: 354-362. [Crossref]

2. Inoue M, Tsugane S (2005) Epidemiology of gastric cancer in Japan. Postgrad Med J 81: 419-424. [Crossref]

3. Sasako M, Sano T, Yamamoto S, Kurokawa Y, Nashimoto A, et al. (2008) D2 lymphadenectomy alone or with para-aortic nodal dissection for gastric cancer. $N$ Engl J Med 359: 453-462. [Crossref]

4. Saidi RF, ReMine SG, Dudrick PS, Hanna NN (2006) Is there a role for palliative gastrectomy in patients with stage IV gastric cancer? World J Surg 30: 21-27. [Crossref]

5. Parkin DM, Bray F, Ferlay J, Pisani P (2005) Global cancer statistics, 2002. CA Cancer J Clin 55: 74-108. [Crossref]

6. Miner TJ, Jaques DP, Karpeh MS, Brennan MF (2004) Defining palliative surgery in patients receiving noncurative resections for gastric cancer. J Am Coll Surg 198: 10131021. [Crossref]

7. McCahill LE, Smith DD, Borneman T, Juarez G, Cullinane C, et al. (2003) A prospective evaluation of palliative outcomes for surgery of advanced malignancies. Ann Surg Oncol 10: 654-663. [Crossref]

8. Hirahara N, Matsubara T, Hayashi H, Takai K, Fujii Y, et al. (2015) Impact of inflammation-based prognostic score on survival after curative thoracoscopic esophagectomy for esophageal cancer. Eur J Surg Oncol 41: 1308-1315. [Crossref]

9. Lamb GW, Aitchison M, Ramsey S, Housley SL, McMillan DC (2012) Clinical utility of the Glasgow Prognostic Score in patients undergoing curative nephrectomy for renal clear cell cancer: basis of new prognostic scoring systems. Br J Cancer 106: 279-283. [Crossref]

10. Tartour E, Dorval T, Mosseri V, Deneux L, Mathiot C, et al. (1994) Serum interleukin 6 and C-reactive protein levels correlate with resistance to IL-2 therapy and poor survival in melanoma patients. Br J Cancer 69: 911-913. [Crossref]

11. Nozoe T, Iguchi T, Egashira A, Adachi E, Matsukuma A, et al. (2011) Significance of modified Glasgow prognostic score as a useful indicator for prognosis of patients with 
gastric carcinoma. Am J Surg 201: 186-191. [Crossref]

12. Dutta S, Al-Mrabt NM, Fullarton GM, Horgan PG, McMillan DC (2011) A comparison of POSSUM and GPS models in the prediction of post-operative outcome in patients undergoing oesophago-gastric cancer resection. Ann Surg Oncol 18: 2808-2817. [Crossref]

13. Japanese Gastric Cancer Association (2011) Japanese gastric cancer treatment guidelines 2010 (ver. 3). Gastric Cancer 14: 101-112. [Crossref]

14. Toiyama Y, Miki C, Inoue Y, Tanaka K, Mohri Y, Kusunoki M (2011) Evaluation of an inflammation-based prognostic score for the identification of patients requiring postoperative adjuvant chemotherapy for stage II colorectal cancer. Exp Ther Med 2: 95-101. [Crossref]

15. Hartgrink HH, Putter H, Klein Kranenbarg E, Bonenkamp JJ, van de Velde CJ; Dutch Gastric Cancer Group (2002) Value of palliative resection in gastric cancer. Br J Surg 89: 1438-1443. [Crossref]

16. Kikuchi S, Arai Y, Morise M, Kobayashi N, Tsukamoto H, et al. (1998) Gastric cancer with metastases to the distant peritoneum: a 20-year surgical experience. Hepatogastroenterology 45: 1183-1188. [Crossref]

17. Maekawa S, Saku M, Maehara Y, Sadanaga N, Ikejiri K, et al. (1996) Surgical treatmen for advanced gastric cancer. Hepatogastroenterology 43: 178-186. [Crossref]

18. Fujitani K, Yang HK, Mizusawa J, Kim YW, Terashima M, et al. (2016) Gastrectomy plus chemotherapy versus chemotherapy alone for advanced gastric cancer with a single non-curable factor (REGATTA): a phase 3, randomised controlled trial. Lancet Oncol 17: 309-318. [Crossref]

19. Coussens LM, Werb Z (2002) Inflammation and cancer. Nature 420: 860-867. [Crossref]

20. O'Callaghan DS, O'Donnell D, O'Connell F, O'Byrne KJ (2010) The role of inflammation in the pathogenesis of non-small cell lung cancer. $J$ Thorac Oncol 5: 2024-2036. [Crossref]

21. Roxburgh CS, McMillan DC (2010) Role of systemic inflammatory response in predicting survival in patients with primary operable cancer. Future Oncol 6: 149-163. [Crossref]
22. Du Clos TW (2000) Function of C-reactive protein. Ann Med 32: 274-278. [Crossref]

23. Forrest LM, McMillan DC, McArdle CS, Angerson WJ, et al. (2005) A prospective longitudinal study of performance status, an inflammation-based score (GPS) and survival in patients with inoperable non-small-cell lung cancer. Br J Cancer 92: 18341836. [Crossref]

24. McMillan DC, Elahi MM, Sattar N, Angerson WJ, Johnstone J, (2001) Measurement of the systemic inflammatory response predicts cancer-specific and non-cancer survival in patients with cancer. Nutr Cancer 41: 64-69. [Crossref]

25. Al-Shaiba R, McMillan DC, Angerson WJ, Leen E, McArdle CS, et al. (2004) The relationship between hypoalbuminaemia, tumour volume and the systemic inflammatory response in patients with colorectal liver metastases. Br J Cancer 91: 205-207. [Crossref]

26. Lien YC, Hsieh CC, Wu YC, Hsu HS, Hsu WH, et al. (2004) Preoperative serum albumin level is a prognostic indicator for adenocarcinoma of the gastric cardia. $J$ Gastrointest Surg 8: 1041-1048. [Crossref]

27. Lee J, Lim T, Uhm JE, Park KW, Park SH, et al. (2007) Prognostic model to predict survival following first-line chemotherapy in patients with metastatic gastric adenocarcinoma. Ann Oncol 18: 886-891. [Crossref]

28. Kubota T, Hiki N, Nunobe S, Kumagai K, Aikou S, et al. (2012) Significance of the inflammation-based Glasgow prognostic score for short- and long-term outcomes after curative resection of gastric cancer. J Gastrointest Surg 16: 2037-2044. [Crossref]

29. Sun J, Song Y, Wang Z, Chen X, Gao P, et al. (2013) Clinical significance of palliative gastrectomy on the survival of patients with incurable advanced gastric cancer: a systematic review and meta-analysis. BMC Cancer 13: 577. [Crossref]

30. Fujitani K, Yamada M, Hirao M, Kurokawa Y, Tsujinaka T (2011) Optimal indications of surgical palliation for incurable advanced gastric cancer presenting with malignant gastrointestinal obstruction. Gastric Cancer 14: 353-359. [Crossref]

31. Roy A, Kim M, Christein J, Varadarajulu S (2012) Stenting versus gastrojejunostomy for management of malignant gastric outlet obstruction: comparison of clinical outcomes and costs. Surg Endosc 26: 3114-3119. [Crossref]

Copyright: $\odot 2017$ Matsubara T. This is an open-access article distributed under the terms of the Creative Commons Attribution License, which permits unrestricted use, distribution, and reproduction in any medium, provided the original author and source are credited. 